\title{
Assessment of Commercial Soybean Cultivars for Resistance Against Prevalent Heterodera glycines Populations of South Dakota
}

\author{
K. Acharya, C. Tande, and E. Byamukama, ${ }^{\dagger}$ Agronomy, Horticulture, and Plant Science Department, South Dakota State University, \\ Brookings 57007
}

Current address: A. Acharya, Department Plant Pathology, North Dakota State University, Fargo 58105

Accepted for publication 30 May 2017.

\section{Abstract}

Soybean cyst nematode (SCN; Heterodera glycines) is the most important yield limiting factor of soybean production in South Dakota and the main management practice is planting SCNresistant cultivars. The effectiveness of host resistance is often limited by the diversity of SCN populations that can reproduce on resistant varieties. A greenhouse study was set up to determine the response of SCN-resistant commercial soybean cultivars with $\mathrm{PI}$ 88788 as the source of SCN resistance genes to the three commonly found SCN H. glycines (HG) types in South Dakota. To screen the soybean cultivars, 3,000 SCN eggs and juveniles of the prevalent HG types $0,2.5 .7$, and 7 were each inoculated to 34 commercial soybean cultivars and also a susceptible cultivar, Williams
82 , as the control. The female index (FI) was calculated based on the average number of females (cysts) found on each cultivar relative to the susceptible check after 35 days. Cultivars showed a varied response to HG types with all 34 cultivars showing resistance or moderate resistance to $\mathrm{HG} 0$. Less than $9 \%$ of the cultivars tested had resistance response and between 82 to $88 \%$ had moderate resistance response to both $\mathrm{HG} 7$ and 2.5 .7 types. Only one cultivar was rated as susceptible to both HG 7 and 2.5.7. These results indicate that host resistance is still effective in managing SCN in South Dakota. However, use of these cultivars should be combined with crop rotation and rotation within soybean cultivars derived from different resistance sources for sustainable SCN management.
Soybean (Glycine max) is one of the important leguminous crops in the United States and is ranked second after corn in terms of production and productivity (USDA-NASS 2012). North America and South America alone contribute about $80 \%$ of the world soybean production (Chang et al. 2015). Yield limiting factors for soybean production includes several biotic and abiotic factors, and among the biotic factors, soybean cyst nematode (SCN; Heterodera glycines Ichinohe) is ranked first (Hartman et al. 2011; Koenning and Wrather 2010).

Soybean cyst nematode is an obligate endo-parasitic nematode that infects soybean roots and its parasitism leads to poor soybean growth and development culminating in yield losses (Schmitt et al. 2004). SCN was first reported in the United States in 1954 in North Carolina (Winstead et al. 1955) and has spread through the Midwest and now has been identified in most of the soybean fields in the United States (Tylka and Marett 2014). In South Dakota, SCN was first detected in Union County in 1995 (Smolik et al. 1996) and is currently found in 29 (mainly eastern-most) counties (Acharya et al. 2014).

Different management strategies have been used to manage soybean cyst nematode, but host resistance and nonhost crop rotation are the most common and affordable methods. These practices also were found to be more effective than chemical control (Niblack et al. 2003; Schmitt et al. 2004; Oyekanmi and Fawole 2010). Although several sources of SCN-resistance genes are available, over $95 \%$ of the SCN-resistant cultivars on the market have one source of SCNresistance genes, PI 88788 (Tylka et al. 2015). The limited diversity of SCN resistance in commercial soybean cultivars poses challenges

${ }^{\dagger}$ Corresponding author. E-mail: Emmanuel.byamukama@sdstate.edu

(C) 2017 The American Phytopathological Society where continued use of the same source of resistance can lead to adapted SCN populations to develop (Mitchum 2016; Niblack et al. 2008).

Although the majority of commercial SCN-resistant cultivars are derived from one resistance source (PI 88788), there are still variations within these cultivars, since $\mathrm{SCN}$ resistance is controlled by several host genes that are inherited differently in soybean cultivars. However, little is known about the SCN-resistant cultivar responses to the different virulence phonotypes of $H$. glycines in South Dakota. Recent research conducted in the state, reported eight H. glycines (HG) types $0,2.5 .7$, and 7 to be the most prevalent among the 73 tested populations tested (Acharya et al. 2016). For the current SCN-resistant cultivars, no information is available on their effectiveness against these prevalent HG types. Such knowledge is important in understanding the effectiveness and durability of the resistance sources used for resistant cultivar breeding. Additionally, producer choices can be limited by the lack of information about the resistant cultivars' source of resistance or the races against which they are effective (Niblack et al. 2009).

Some greenhouse studies that screened resistance of commercial cultivars against the different HG type populations in Illinois, Iowa, and Missouri found that cultivars labeled resistant to specific races or HG types showed different resistance reactions (Koenning, 2004; Faghihi, 2006; Hershman et al. 2008; Tylka et al. 2015). Although there is variability in resistance responses of the commercial cultivars, yield benefit can still be obtained by planting resistant cultivars. In a study done in Minnesota, planting of a resistant soybean cultivar showed a $28.4 \%$ yield benefit over the susceptible cultivar (Chen et al. 2001). Similarly, a comprehensive study of SCN-resistant cultivars' performance under varying SCN pressure also consistently showed yield benefit compared with susceptible cultivars in Iowa (Tylka et al. 2015). 


\begin{tabular}{|c|c|c|c|}
\hline \multicolumn{4}{|c|}{$\begin{array}{l}\text { TABLE } 1 \\
\text { List of commercial soybean cultivars marketed as soybean } \\
\text { cyst nematode resistant that were used for screening for } \\
\text { resistance against prevalent HG types in South Dakota } \\
\text { under greenhouse conditions }\end{array}$} \\
\hline $\begin{array}{l}\text { Cultivars } \\
\text { name }\end{array}$ & $\begin{array}{l}\text { Relative } \\
\text { maturity }\end{array}$ & $\begin{array}{l}\text { Source of SCN } \\
\text { resistance }\end{array}$ & $\begin{array}{l}\text { Company/ } \\
\text { industry }\end{array}$ \\
\hline PB-1 & 0.3 & PI 88788 & Prairie Brand \\
\hline PB-2 & 0.6 & PI 88788 & Prairie Brand \\
\hline Syn-1 & 0.6 & R3, MR14/ PI88788 & Syngenta \\
\hline PB-3 & 0.7 & PI 88788 & Prairie Brand \\
\hline AG-1 & 0.8 & $\mathrm{R} 3$ & Asgrow \\
\hline PB-4 & 0.8 & PI 88788 & Prairie Brand \\
\hline PB-5 & 0.8 & Resistant & Prairie Brand \\
\hline AG-2 & 0.9 & $\mathrm{R} 3$ & Asgrow \\
\hline PB-6 & 0.9 & PI 88788 & Prairie Brand \\
\hline Syn-2 & 0.9 & R3, MR14/ PI88788 & Syngenta \\
\hline AG-3 & 1.1 & $\mathrm{R} 3$ & Asgrow \\
\hline PB-7 & 1.1 & PI 88788 & Prairie Brand \\
\hline AG-4 & 1.2 & $\mathrm{R} 3$ & Asgrow \\
\hline PB-8 & 1.2 & PI 88788 & Prairie Brand \\
\hline AG-5 & 1.4 & $\mathrm{R} 3$ & Asgrow \\
\hline PB-9 & 1.4 & PI 88788 & Prairie Brand \\
\hline PB-10 & 1.5 & PI 88788 & Prairie Brand \\
\hline AG-6 & 1.7 & $\mathrm{R} 3$ & Asgrow \\
\hline PB-11 & 1.7 & PI 88788 & Prairie Brand \\
\hline PB-12 & 1.8 & PI 88788 & Prairie Brand \\
\hline AG-7 & 1.9 & $\mathrm{R} 3$ & Asgrow \\
\hline PB-13 & 1.9 & PI 88788 & Prairie Brand \\
\hline PB-14 & 1.9 & PI 88788 & Prairie Brand \\
\hline AG-8 & 2 & $\mathrm{R} 3$ & Asgrow \\
\hline AG-9 & 2.1 & $\mathrm{R} 3$ & Asgrow \\
\hline Syn-3 & 2.2 & R3, MR14/ PI88788 & Syngenta \\
\hline AG-10 & 2.3 & $\mathrm{R} 3$ & Asgrow \\
\hline AG-11 & 2.4 & MR3 & Asgrow \\
\hline AG-12 & 2.5 & R3 & Asgrow \\
\hline AG-13 & 2.6 & $\mathrm{R} 3$ & Asgrow \\
\hline Syn-4 & 2.6 & R3, MR14/ PI88788 & Syngenta \\
\hline AG-14 & 2.7 & MR3 & Asgrow \\
\hline AG-15 & 2.8 & R3 & Asgrow \\
\hline AG-16 & 2.9 & $\mathrm{R} 3$ & Asgrow \\
\hline Williams 82 & 3.9 & Susceptible & Susceptible check \\
\hline
\end{tabular}

Agronomic performance of the currently available soybean commercial cultivars against prevalent HG types in South Dakota can provide growers with vital information to guide them in selecting suitable resistant cultivars and to inform future plant breeding efforts for SCN resistance. The objective of this study was to screen SCNresistant commercial cultivars of different relative maturities ranging from 0.8 to 3.9 against $\mathrm{HG}$ types $0,2.5 .7$, and 7, the most prevalent H. glycines populations present in South Dakota.

\section{Cultivar Selection and Screening}

A total of 34 commercial soybean cultivars were selected from Asgrow, Prairie Brand, and Syngenta based upon the relative maturity and SCN resistance sources (Table 1). These cultivars were either labeled with source of resistance (PI 88788) or "resistant to race 3 " or "moderately resistant to race 14 " in the seed catalogs. Williams 82 was used as the susceptible check.
TABLE 2

Classification of the soybean cultivars for resistance

or susceptibility to the soybean cyst nematode based on

the female index on each of the cultivar (Schmitt and Shannon 1992)

\begin{tabular}{lll} 
Female index (\%) & \multicolumn{1}{c}{ Rating } & Label \\
$<10$ & Resistant & R \\
10 to 30 & Moderately resistant & MR \\
31 to 60 & Moderately susceptible & MS \\
$>60$ & Susceptible & S \\
\hline
\end{tabular}

\begin{tabular}{|c|c|c|c|}
\hline \multicolumn{4}{|c|}{ 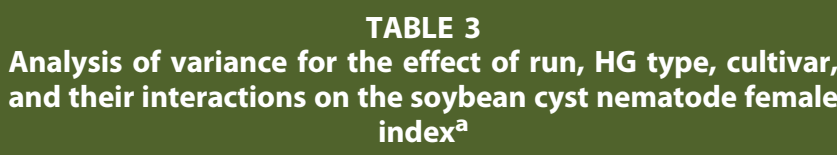 } \\
\hline Effect & $D^{b} \mathbf{b}$ & F-value & $\operatorname{Pr}^{\mathrm{C}}>\mathrm{F}$ \\
\hline Run & 1 & 5.17 & 0.0233 \\
\hline HG type & 2 & 61.06 & $<0.0001$ \\
\hline Cultivar & 33 & 20.05 & $<0.0001$ \\
\hline Run*Cultivar & 33 & 0.84 & 0.7304 \\
\hline HG type*Cultivar & 66 & 1.34 & 0.0421 \\
\hline Run*HG type & 2 & 3.85 & 0.0217 \\
\hline Run*HG type*Cultivar & 66 & 1.02 & 0.4318 \\
\hline
\end{tabular}

${ }^{a}$ Female index was the number of cysts on a cultivar divided by the number of cysts on the susceptible check $\times 100 \%$.

${ }^{\mathrm{b}} \mathrm{DF}=$ Degree of freedom.

${ }^{\mathrm{c}} \operatorname{Pr}=$ probability.

The SCN HG types were selected based on a study by Acharya et al. 2016 that indicated HG types 0, 2.5.7, and 7 to be the most prevalent in South Dakota. The populations of these three HG types were increased by inoculating the susceptible cultivar, Williams 82 , in the greenhouse. HG type 0 was obtained from Union County while HG types 2.5.7 and 7 were obtained from Turner County. Cysts for each HG type were processed by extraction of eggs and juveniles from cysts of each HG type following procedures by Faghihi and Ferris (2000).

Seeds of each cultivar were directly planted into cones $(3.8 \mathrm{~cm}$ wide, $21 \mathrm{~cm}$ tall; Stuewe and Sons Inc., Tangent, OR) filled with a sterilized soil mixture ( 2 parts sand: 1 part clay loam soil) by volume. Extra seedlings were thinned from each container immediately after germination leaving one seedling per cone. Each cultivar, including the susceptible check, was replicated four times for each HG type of the $H$. glycines populations and the completely randomized design was used. $\mathrm{SCN}$ eggs and juveniles of each $\mathrm{HG}$ type were counted under the dissecting microscope, and each cultivar was inoculated with 3,000 eggs and juveniles. Inoculation was done at the time of planting. After planting, cones were put in a 2-gal bucket filled with sand and were kept in a water bath at 25 to $28^{\circ} \mathrm{C}$ in the greenhouse. The greenhouse was maintained at 27 to $28^{\circ} \mathrm{C}$ and $16 \mathrm{~h}$ of daylight. After 35 days, the containers were taken out of the water bath and soaked in water for $15 \mathrm{~min}$ and then plants were uprooted gently and washed in a 710- $\mu$ m-pore sieve nested over a $250-\mu \mathrm{m}$-pore sieve with pressurized tap water to release the cysts from the roots. Released cysts were counted under the dissecting microscope for the determination of the female index. The number of cysts present on the roots of each of the commercial and susceptible cultivars was counted and used for calculating the female index (FI). The female index for each of the cultivars and $\mathrm{HG}$ types was calculated as: $\mathrm{FI}=$ [avg. no. of cysts found on commercial 
TABLE 4

Number of cysts, female index, and resistance classification for commercial soybean cultivars inoculated with soybean cyst nematode HG types $\mathbf{0}, 7$, and 2.5 .7 under greenhouse conditions during the first run

\begin{tabular}{|c|c|c|c|c|c|c|c|c|c|}
\hline \multirow[b]{2}{*}{ Cultivar series } & \multicolumn{3}{|c|}{ HG type 0} & \multicolumn{3}{|c|}{ HG type 7} & \multicolumn{3}{|c|}{ HG type 2.5.7 } \\
\hline & No. of cysts ${ }^{a}$ & Female index (\%) & Label $^{b}$ & No. of cysts & Female index (\%) & Label & No. of cysts & Female index (\%) & Label \\
\hline 1 & 5 & 2.76 & $\mathrm{R}$ & 17 & 10.63 & MR & 15 & 9.95 & $\mathrm{R}$ \\
\hline 3 & 8 & 5.05 & $\mathrm{R}$ & 25 & 15.47 & MR & 24 & 16.02 & MR \\
\hline 4 & 8 & 5.05 & $\mathrm{R}$ & 34 & 20.94 & MR & 20 & 13.49 & MR \\
\hline 5 & 10 & 5.97 & $\mathrm{R}$ & 28 & 17.34 & MR & 23 & 15.68 & MR \\
\hline 8 & 11 & 6.7 & $\mathrm{R}$ & 25 & 15.31 & MR & 35 & 23.27 & MR \\
\hline 9 & 11 & 6.89 & $\mathrm{R}$ & 31 & 19.38 & MR & 23 & 15.18 & MR \\
\hline 10 & 12 & 7.04 & $\mathrm{R}$ & 19 & 12.03 & MR & 32 & 21.25 & MR \\
\hline 11 & 13 & 7.66 & $\mathrm{R}$ & 47 & 29.22 & MR & 39 & 26.14 & MR \\
\hline 12 & 13 & 7.66 & $\mathrm{R}$ & 5 & 2.97 & $\mathrm{R}$ & 26 & 17.71 & MR \\
\hline 17 & 15 & 9.19 & $\mathrm{R}$ & 27 & 16.88 & MR & 39 & 25.97 & MR \\
\hline 18 & 16 & 9.8 & $\mathrm{R}$ & 31 & 19.53 & MR & 29 & 19.39 & MR \\
\hline 19 & 16 & 9.8 & $\mathrm{R}$ & 170 & 106.09 & S & 125 & 84.15 & S \\
\hline 20 & 16 & 9.8 & $\mathrm{R}$ & 32 & 20.16 & MR & 33 & 22.43 & MR \\
\hline 21 & 16 & 9.95 & $\mathrm{R}$ & 41 & 25.47 & MR & 27 & 17.88 & MR \\
\hline 22 & 17 & 10.41 & MR & 49 & 30.63 & MS & 35 & 23.61 & MR \\
\hline 23 & 17 & 10.41 & MR & 34 & 21.09 & MR & 26 & 17.2 & MR \\
\hline 24 & 18 & 10.72 & MR & 52 & 32.66 & MS & 31 & 20.91 & MR \\
\hline 25 & 18 & 10.72 & MR & 24 & 14.84 & MR & 16 & 10.79 & MR \\
\hline 26 & 21 & 12.71 & MR & 33 & 20.31 & MR & 25 & 16.86 & MR \\
\hline 27 & 22 & 13.32 & MR & 46 & 28.59 & MR & 34 & 22.6 & MR \\
\hline
\end{tabular}

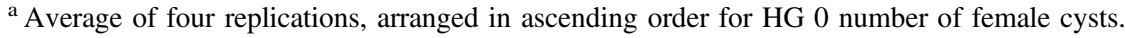

${ }^{\mathrm{b}} \mathrm{R}=$ Resistant $(\mathrm{FI}<10 \%), \mathrm{MR}=$ moderately resistant $(\mathrm{FI}=10$ to $30 \%), \mathrm{MS}=$ moderately susceptible $(\mathrm{FI}=31$ to $60 \%), \mathrm{S}=$ susceptible $(\mathrm{FI}>60 \%)$.

cultivar/avg. no. of cysts found on susceptible cultivar] $\times 100$. Cultivars were classified as resistant, moderately resistant, moderately susceptible, or susceptible based on the FI level as described by Schmitt and Shannon (1992) (Table 2). The experiment was repeated once (two experimental runs).

Analysis of variance was used to determine the effect of run, cultivar, and HG type on the female index for each cultivar at $P=$ 0.05. Pearson's $\chi^{2}$ (PROC FREQ SAS 9.3; SAS Institute Inc., Cary, NC) was used to test the hypothesis that the number of cultivars classified as resistant, moderately resistant, moderately susceptible or susceptible was the same across the three HG types.

\section{Reproduction of the Three HG Types on the Cultivars}

The effects of run, cultivar, and HG type were significant $(P<$ $0.05)$; however, cultivar $\times$ run was not significant, indicating that the cultivars followed a similar pattern in both runs (Table 3). HG type by run interaction was significant and therefore the two runs were analyzed separately. In the first greenhouse run, significant differences were observed in mean number of females that developed on the cultivars tested between $\mathrm{HG}$ type 0,7 , and 2.5.7 $(P<$ 0.0001 ), leading to different resistance/susceptibility classification of the cultivars among the three HG types (Table 4).

Out of the 34 cultivars inoculated with $\mathrm{HG}$ type 0,21 cultivars showed a resistant response $(\mathrm{FI}<10 \%)$ and 13 showed a moderately resistant response ( $\mathrm{FI}=10$ to $30 \%$ ). None of the cultivars tested showed a moderately susceptible (FI $=31$ to $60 \%$ ) or susceptible (FI $>60 \%$ ) response when inoculated with HG 0 (Fig. 1). For HG type 7 inoculation, one cultivar was resistant, 28 cultivars were moderately resistant, 5 cultivars were moderately susceptible, and one cultivar showed a susceptible reaction (Fig. 2). For HG type 2.5.7 populations, out of the 34 cultivars, 2 cultivars were resistant, 30 cultivars were moderately resistant, one cultivar was moderately susceptible, and one cultivar was susceptible. These results indicate 


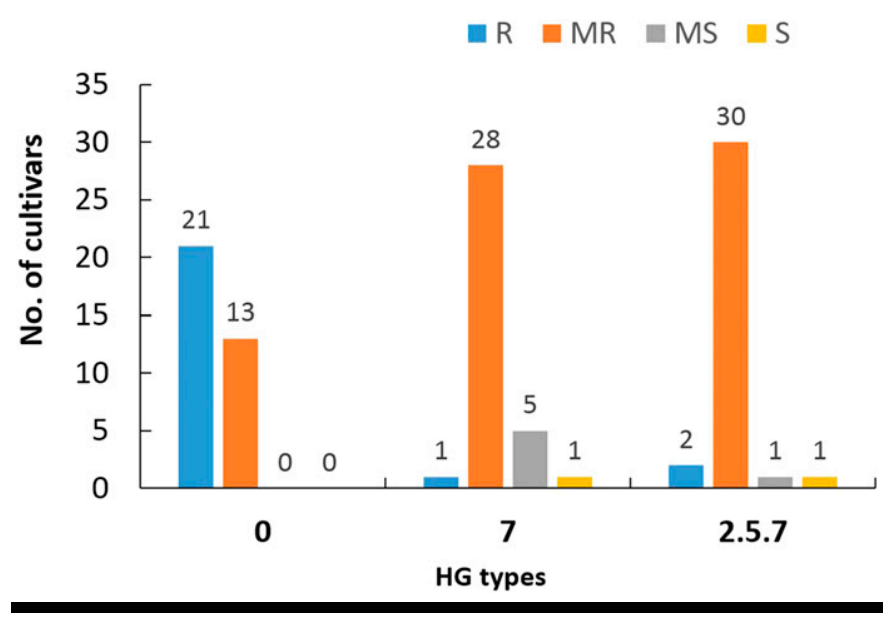

FIGURE 1

Frequency of cultivars assessed as resistant $(\mathrm{R},<10 \% \mathrm{FI})$, moderately resistant ( $M R, F I=10$ to $30 \%$ ), moderately susceptible (MS, FI = 31 to $60 \%$ ), or susceptible (S, Fl > 60\%) against three types of Heterodera glycines populations under greenhouse conditions during the first run.

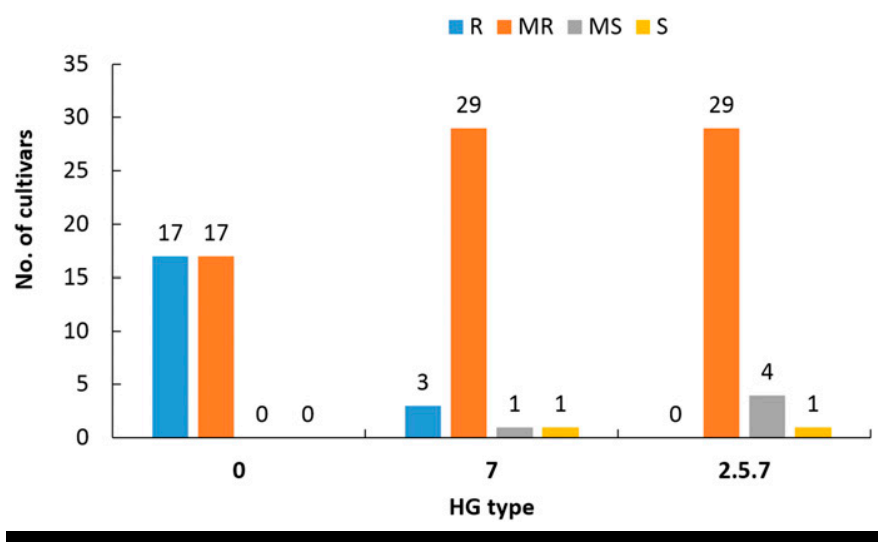

FIGURE 2

Frequency of cultivars assessed as resistant $(\mathrm{R},<10 \% \mathrm{Fl})$, moderately resistant (MR, $\mathrm{FI}=10$ to $30 \%$ ), moderately susceptible (MS, FI $=31$ to $60 \%$ ), or susceptible $(\mathrm{S}, \mathrm{Fl}>60 \%)$ against three types of Heterodera glycines populations under greenhouse conditions during the second run.

that $\mathrm{HG}$ type 0 had the highest number of cultivars ranked as either resistant or moderately resistant. HG type 0 refers to SCN population that can be managed by any of the current seven sources of SCN resistance genes (Niblack et al. 2009). Acharya et al. (2016) reported that $\mathrm{HG}$ type 0 was the most predominant of the $73 \mathrm{SCN}$ populations that were tested in South Dakota. The fact that the commercial cultivars marketed as SCN resistant were found to be either resistant or moderately resistant to $\mathrm{HG}$ type 0 is good news for soybean growers in South Dakota. Other studies reported HG type 0 had increased reproduction on SCN resistant cultivars with PI 88788 source of resistance (Heydari et al. 2009).

Female indices for cultivars rated as moderately resistant ranged from 10 to $19 \%$ under HG type 0 inoculation, and 11 to $30 \%$ for both HG type 7 and 2.5.7 inoculations (Table 4). For cultivars rated as moderately susceptible, FI was 31 to $33 \%$ for HG type 0,32 to $34 \%$ for $\mathrm{HG}$ type 7 , and 31 to $38 \%$ for $\mathrm{HG}$ type 2.5.7. One cultivar was rated as susceptible for both HG type 7 and HG type 2.5.7 and had FI of $107 \%$ and $84 \%$, respectively.
In the second run, generally similar results as first run were observed in mean number of female cysts that developed on the cultivars tested for HG type 0, 7, and 2.5.7 (Table 5). Out of the 34 cultivars tested for HG type 0,17 cultivars showed a resistant response and 17 showed a moderately resistant response. As in the first run, none of the cultivars inoculated with HG type 0 had a moderately susceptible or susceptible response. For HG type 7, out of the 34 cultivars, 3 cultivars were resistant, 29 cultivars were moderately resistant, two cultivars were moderately susceptible, and one cultivar was susceptible. For HG type 2.5.7, out of the 34 cultivars, none of the cultivars showed a resistant response, 29 cultivars showed a moderately resistant response, 4 cultivars showed a moderately susceptible response, and one cultivar showed a susceptible response (Fig. 2).

The female indices ranges in the second run were similar to those in the first run. For cultivars rated as moderately resistant, FI ranged from 10 to $20 \%$ for $\mathrm{HG}$ type 0 inoculation, 11 to $22 \%$ for $\mathrm{HG}$ type 7, and 10 to $29 \%$ for HG type 2.5.7 (Table 5). Moderately susceptible cultivars had an FI of 33 to $51 \%$ for HG 7 and 31 to $36 \%$ for HG 2.5.7. One cultivar was rated as susceptible and had $102 \%$ FI for HG 7 and $65 \%$ for HG 2.5.7. Although the resistance source was the same for all the cultivars evaluated, variation in the female indices was observed. This might be due to the differences in inheritance of resistant genes from the PI line 88788, since SCN resistance is controlled by several gens. Previously, it was suggested that in field conditions, the maturity group of the soybean cultivar could also have an effect in the resistance and susceptible reaction as illustrated in a research study by Koenning et al. (1993). In our experiment, we did not detect any correlation between the maturity group and the resistance reaction against all the three $H$. glycines population $(P=0.05)$ under greenhouse conditions.

The HG type that was inoculated to each soybean cultivar influenced the classification of that cultivar as either resistant, moderately resistant, moderately susceptible, or susceptible in both runs (first run, $\chi^{2}=38.22, P$-value $<0.0001$; second run, $\chi^{2}=32.17, P$-value $\left.<0.0001\right)$. HG type 0 tended to have a higher percentage of the cultivars tested to be classified as resistant or moderately resistant, whereas HG types 7 and 2.5.7 had more cultivars classified as moderately resistant or moderately susceptible in both runs. Only one of the cultivars marketed as resistant to HG type 0 was found to be moderately susceptible to this HG type and was rated susceptible to HG types 7 and 2.5.7 in both runs (Figs. 1 and 2).

HG types 7 and 2.5.7 were more aggressive than HG type 0 because of the number of cultivars that were grouped as moderately susceptible or susceptible $\left(\chi^{2}=32.56 P<0.0001\right)$. This is not surprising as similar findings have been reported where resistance genes overcome by HG type 2.5.7 can also be overcome by HG type 7 (Anand and Brar 1983). This is thought to be due to HG type indicator lines \#2, \#5, and \#7 being categorized as PI 88788 group and their resistance mechanism is through induction of slower nuclear degradation of plant cells at the nematode feeding site (Colgrove and Niblack 2008).

\section{Conclusions and Recommendations}

The results obtained from this study indicated that most of the commercial cultivars showed a resistant reaction to HG type 0 and a moderately resistant reaction to $\mathrm{HG}$ types 2.5.7 and 7. Response of these $\mathrm{SCN}$ resistant cultivars to $H$. glycines populations in this study suggested that host resistance is effective in SCN management in South Dakota. These findings agree with other research studies in different states in the United States that indicated the resistance 
TABLE 5

Number of cysts, female index, and resistance classification for commercial soybean cultivars inoculated with soybean cyst nematode HG types $\mathbf{0 , 7}$, and 2.5 .7 under greenhouse conditions during the second run

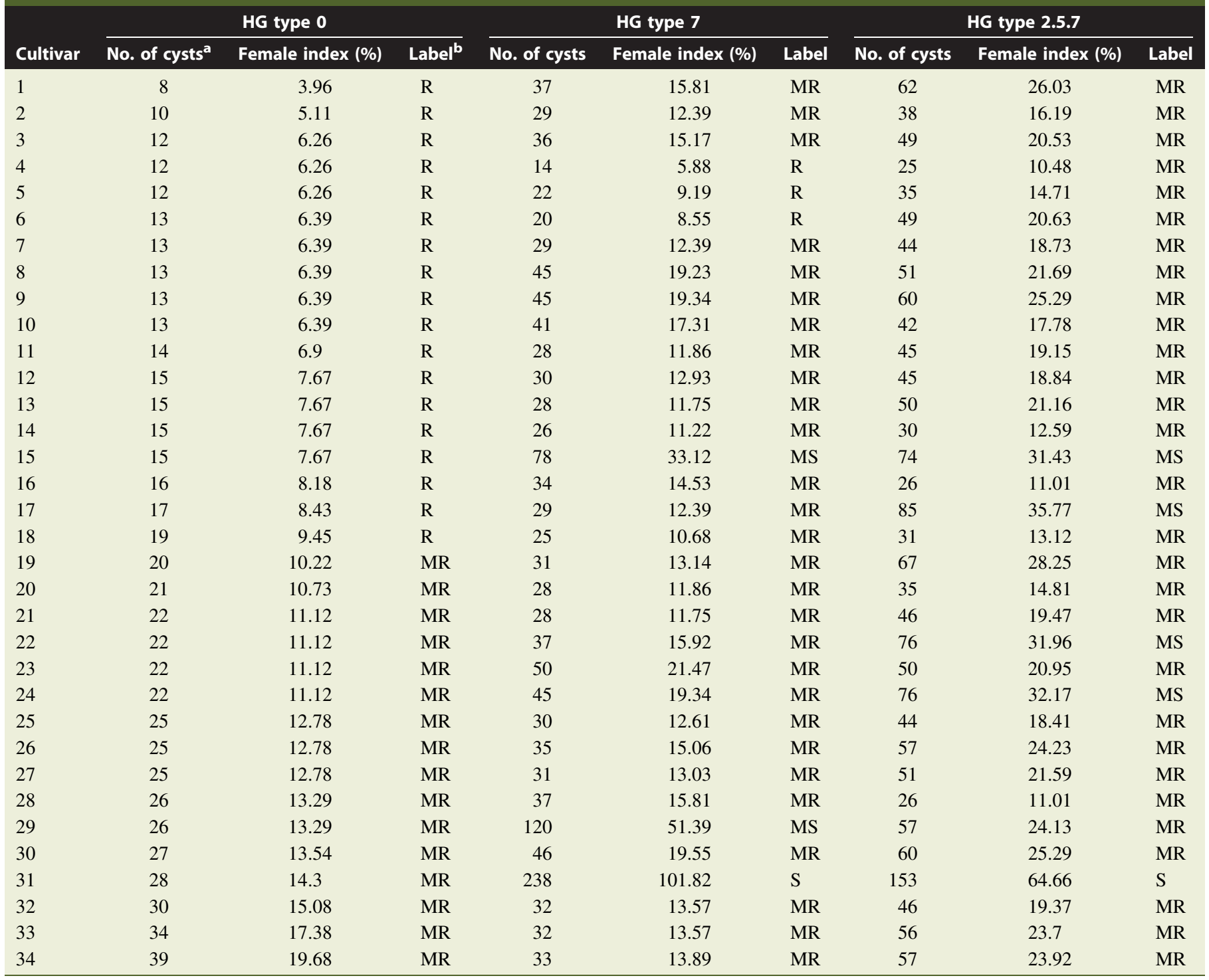

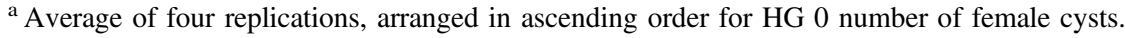

${ }^{\mathrm{b}} \mathrm{R}=$ Resistant $(\mathrm{FI}<10 \%), \mathrm{MR}=$ moderately resistant $(\mathrm{FI}=10$ to $30 \%), \mathrm{MS}=$ moderately susceptible $(\mathrm{FI}=31$ to $60 \%), \mathrm{S}=$ susceptible $(\mathrm{FI}>60 \%)$.

genes from PI 88788 to be still effective (Chen et al. 2001; Davis et al. 1996; Koenning, 2004).

Knowledge of the SCN resistant source and the Heterodera glycines HG types is very important in managing soybean cyst nematode. This knowledge can aid growers in selecting resistant cultivars specific to the HG type present in their fields. Although the majority of commercial cultivars marketed as resistant to SCN were either classified as moderately resistant or moderately susceptible in our study, the FI for these cultivars were less than $35 \%$ across the three HG types. These results suggest that host resistance is effective as a SCN management practice in South Dakota. However, because SCN can still reproduce on some of these lines, host resistance should be integrated with other management practices such as nonhost crop rotation for sustainable management of SCN. Further research is needed to determine the response of commercial cultivars to other HG types and the effect of different HG types on soybean yield and yield components.

\section{Acknowledgments}

Support for this research was provided by South Dakota Soybean Research and Promotion Council and USDA-NIFA Hatch through South Dakota State University Agricultural Experiment Station. We thank the various seed companies for providing the soybean cultivar seed for the study.

\section{Literature Cited}

Acharya, K., Byamukama, E. and Tande, C. 2014. Status of the soybean cyst nematode, Heterodera glycines, in South Dakota. Phytopathology 104:S3.3.

Acharya, K., Tande, C., and Byamukama, E. 2016. Determination of Heterodera glycines virulence phenotypes occurring in South Dakota. Plant Dis. 100: 2281-2286.

Anand, S. C., and Brar, G. S. 1983. Response of soybean lines to differentially selected cultures of soybean cyst nematode Heterodera glycines Ichinohe. J. Nematol. 15:120-123. 
Chang, W. S., Lee, H. I., and Hungria, M. 2015. Soybean Production in the Americas. Pages 393-400 in: Principles of Plant-Microbe Interactions. B. Lugtenberg, ed. Springer, Cham, Switzerland.

Chen, S., Porter, P., Orf, J., Reese, C., Stienstra, W., Young, N., Walgenbach, D., Schaus, P., Arlt, T., and Breitenbach, F. 2001. Soybean cyst nematode population development and associated soybean yields of resistant and susceptible cultivars in Minnesota. Plant Dis. 85:760-766.

Colgrove, A. L., and Niblack, T. L. 2008. Correlation of female indices from virulence assays on inbred lines and field populations of Heterodera glycines. J. Nematol. 40:39-45.

Davis, E., Koenning, S., Burton, J., and Barker, K. 1996. Greenhouse evaluation of selected soybean germplasm for resistance to North Carolina populations of Heterodera glycines, Rotylenchulus reniformis, and Meloidogyne species. J. Nematol. 28:590-598.

Faghihi, J., and Ferris, J. 2006. Soybean Cyst Nematode. Coop. Ext. Serv., Purdue Univ., West Lafayette, IN.

Faghihi, J., and Ferris, J. 2000. An efficient new device to release eggs from Heterodera glycines. J. Nematol. 32:411-413.

Hartman, G. L., West, E. D., and Herman, T. K. 2011. Crops that feed the World 2. Soybean worldwide production, use, and constraints caused by pathogens and pests. Food Secur. 3:5-17.

Hershman, D., Heinz, R., and Kennedy, B. 2008. Soybean cyst nematode, Heterodera glycines, populations adapting to resistant soybean cultivars in Kentucky. Plant Dis. 92:1475.

Heydari, R., Pourjam, E., Tanha, M. Z., and And Safaei, N. 2009. Evaluation of some common soybean cultivars to the major type of the soybean cyst nematode of iran, Heterodera glycines hg type 0. Iranian J. Plant Pathol. 44:319-329.

Koenning, S. 2004. Resistance of soybean cultivars to field populations of Heterodera glycines in North Carolina. Plant Dis. 88:942-950.

Koenning, S., Schmitt, D., and Barker, K. 1993. Effects of cropping systems on population density of Heterodera glycines and soybean yield. Plant Dis. 77: $780-786$
Koenning, S. R., and Wrather, J. A. 2010. Suppression of soybean yield potential in the continental United States by plant diseases from 2006 to 2009. Plant Health Prog. doi:10.1094/PHP-2010-1122-01-RS

Mitchum, M. G. 2016. Soybean resistance to the soybean cyst nematode Heterodera glycines: An update. Phytopathology 106:1444-1450.

Niblack, T., Tylka, G. L., Arelli, P., Bond, J., Diers, B., Donald, P., Faghihi, J., Ferris, V. R., Gallo, K., Heinz, R. D., Lopez Nicora, H., Von Qualen, R., Welacky, T., and Wilcox, J. 2009. A standard greenhouse method for assessing soybean cyst nematode resistance in soybean: SCE08 (standardized cyst evaluation 2008). Plant Health Prog. doi:10.1094/PHP-2009-051301-RV

Niblack, T., Wrather, J., Heinz, R., and Donald, P. 2003. Distribution and virulence phenotypes of Heterodera glycines in Missouri. Plant Dis. 87:929-932.

Niblack, T. L., Colgrove, A. L., Colgrove, K., and Bond, J. P. 2008. Shift in virulence of soybean cyst nematode is associated with use of resistance from PI 88788. Health Prog. doi:10.1094/PHP-2008-0118-01-RS

Oyekanmi, E. O., and Fawole, B. 2010. Nematodes of soybean and their management. Pages 325-344 in: The Soybean: Botany, Production and Uses. G. Singh, ed. CABI, Wallingford, Oxfordshire, UK.

Schmitt, D., and Shannon, G. 1992. Differentiating soybean responses to Heterodera glycines races. Crop Sci. 32:275-277.

Schmitt, D. P., Wrather, J. A., and Riggs, R. D. 2004. Biology and Management of Soybean Cyst Nematode, 2nd Ed. Walsworth Publ. Co., Marceline, MO.

Smolik, J. D., Jones, J. L., Gallenberg, D. L., and Gille, J. P. 1996. First report of Heterodera glycines on soybean in South Dakota. Plant Dis. 80:224

Tylka, G. L., Gebhart, G. D., Marett, C. C., Mullaney, M. P., and 2015. Evaluation of soybean varieties resistant to soybean cyst nematode in Iowa in 2015. Ext. Publ. IPM 52. Iowa State Univ., Ames.

Tylka, G. L., and Marett, C. C. 2014. Distribution of the soybean cyst nematode (Heterodera glycines) in the United States and Canada: 1954 to 2014. Plant Health Prog. 15:85-87.

Winstead, N. N., Skotland, C. B., and Sesser, J. N. 1955. Soybean cyst nematode in North Carolina. Plant Dis. Rep. 39:9-11. 